\title{
Sorption Isotherms of Sheanuts Kernel and Canarium Pulp: Application to Products Dehydration
}

\author{
${ }^{1}$ Gilles Bernard Nkouam, ${ }^{2}$ Cesar Kapseu, ${ }^{3}$ Ali Ahmed, ${ }^{4}$ Danielle Barth and ${ }^{4}$ Michel Dirand \\ ${ }^{1}$ Department of Agriculture, Livestock and By-products, The Higher Institute of the Sahel, \\ University of Maroua, P.O. Box 46, Maroua, Cameroon \\ ${ }^{2}$ Department of Process Engineering, ENSAI University of Ngaoundere, \\ P.O. Box 455, Ngaoundere, Cameroon \\ ${ }^{3}$ Department of Chemical Engineering, IUT University of Ngaoundere, \\ P.O. Box, 455 Ngaoundere, Cameroon \\ ${ }^{4}$ Laboratoire Reactions et Genie des Procedes UPR CNRS 3349 ENSIC-INPL, \\ 1 rue Grandville, BP 20451, 54001 Nancy Cedex, France
}

\begin{abstract}
A comparative study of sorption isotherms of sheanuts kernel and Canarium pulp was conducted at $25,35,45$ and $55^{\circ} \mathrm{C}$. A semi-empirical model was used to determine monolayer energy while an empirical method was used to estimate hysteresis loop energies. Results indicate that Canarium has a thinner hysteresis loop which decreases with increasing temperature. On the contrary, sheanuts kernel hysteresis loop was constant through out the temperature range studied. The estimated energies of the monolayer intermolecular attraction gave a difference of $0.67-0.02 \mathrm{~kJ} \mathrm{~mol}{ }^{1}$ for Canarium which was lower than that of sheanut kernel $\left(1.09-0.29 \mathrm{~kJ} \mathrm{~mol}^{\bullet^{1}}\right)$. The energy of the hysteresis loop of sheanut kernel $\left(103.60-63.89 \mathrm{~kJ}\right.$ mol ${ }^{\cdot 1}$ from $\left.25-55^{\circ} \mathrm{C}\right)$ was higher than that of Canarium pulp $\left(10.18-2.94 \mathrm{~kJ} \mathrm{~mol} \cdot^{1}\right.$ from $\left.25-55^{\circ} \mathrm{C}\right)$. It appears that dehydration of sheanuts kernel requires more energy than Canarium pulp.
\end{abstract}

Key words: Vitellaria paradoxa Gaertn., Canarium schweinfurthii Engl., isotherms, energies, dehydration, hystersis loop

\section{INTRODUCTION}

Isotherms are used in many fields including preservation and food drying. They give knowledge of the limiting water content during a normal drying (Wang and Brennan, 1991). The phenomenon by which at a given temperature and water activity, an adsorbent contains more water during desorption than during adsorption is called hysteresis. A large hysteresis loop is indicative of an easier product preservation but a high energy demand for its drying.

Several non-conventional oilseeds including shea (Vitellaria paradoxa Gaertn.) and Canarium schweinfurthii Engl. called Canarium, occupy a prominent place in tropical countries (Booth and Wickens, 1988). For example, UNIFEM reported that shea was in 1985, the 3rd largest export in the Burkinabe economy with $1.96 \%$ of GDP (Gross Domestic Product). Caurie (2007) has recently developed an equation to describe sorption isotherms on the whole range of water activity. This equation connects water content of the product, water activity, temperature and monolayer intermolecular attraction energy. We propose to adapt this equation to experimental data obtained on sheanut kernel and Canarium pulp from Kapseu et al. (2006). The aim of this research is to determine monolayer intermolecular attraction energies of these two oilseeds in relation to their hysteresis loop energies in order to access energy demands for drying these foodstuffs.

\section{MATERIALS AND METHODS}

Hysteresis equation: In developing the uni-molecular adsorption equation established by Caurie $(2005,2007)$, obtained the following general equation that describes the phenomenon of hysteresis (Eq. 1):

$$
\mathrm{m}\left(\frac{1}{\mathrm{a}}-\mathrm{a}\right)=\mathrm{K} \exp \left(\mathrm{B} \cdot \frac{\mathrm{Q}}{\mathrm{T}}\right)
$$

Where:

$\mathrm{m}=$ Water content at water activity a

$\mathrm{Q} \quad=$ Intermolecular attraction energy $(\mathrm{cal}$ gmol $\mathrm{K} \cdot{ }^{1}$ ) of the monolayer $\mathrm{m}_{0}$

$\mathrm{T}=$ Absolute temperature $\left({ }^{\circ} \mathrm{K}\right)$

$\mathrm{K}$ and $\mathrm{B}=$ Constants

Corresponding Author: Gilles Bernard Nkouam, Department of Agriculture, Livestock and By-products, The Higher Institute of the Sahel, University of Maroua, P.O. Box 46, Maroua, Cameroon 
Estimation of variations of monolayer intermolecular attraction energy (Q): The uni-molecular adsorption equation of Caurie (2005) states that (Eq. 2):

$$
\left(\frac{\mathrm{m}}{\mathrm{m}_{0}}\right)^{\mathrm{n}}=\mathrm{C}\left(\frac{\mathrm{a}}{1-\mathrm{a}}\right)^{2}
$$

Where, $\mathrm{n}$ is the number of adsorption sites. From Eq. $2, \ln \left(\mathrm{m} / \mathrm{m}_{0}\right)$ Vs. $\ln [\mathrm{c} /(1-\mathrm{a})]$ was plotted at each temperature $\left(25,35,45\right.$ and $\left.55^{\circ} \mathrm{C}\right)$. The slope is $2 / \mathrm{n}$ and intercept $\ln (\mathrm{C}) / \mathrm{n}$. $\mathrm{Q}$ was deduced from the Caurie constant $\mathrm{C}$ while $\mathrm{K}$ and $\mathrm{B}$ were deduced from $\mathrm{m}$ and $\mathrm{a}$.

The values of the monolayer moisture content $\mathrm{m}_{0}$ (dry basis) are experimental values obtained from the GAB equation. To calculate the variations of $Q$, the data used in desorption are only moisture content, the water activities remain the same.

Hysteresis loops energy calculation: Nkouam obtained satisfactory correlations $\left(\mathrm{R}^{2}=0.99\right)$ between the isosteric sorption heat $(\mathrm{Qs})$ and moisture content $(\mathrm{M})$ of sheanut kernel and Canarium pulp (Eq. 3-6).

Shea:

$$
\begin{aligned}
& \text { Adsorption: } \mathrm{Q}_{\mathrm{s}}=4.39+\frac{17.77}{\mathrm{M}}-\frac{6.17}{\mathrm{M}^{2}}+\frac{10.08}{\mathrm{M}^{3}} \\
& \text { Desorption : } \mathrm{Q}_{\mathrm{s}}=7.12+\frac{21.65}{1+10^{\log 4.13-\mathrm{M}) 4.71}}
\end{aligned}
$$

\section{Canarium:}

$$
\begin{aligned}
& \text { Adsorption: } \mathrm{Q}_{\mathrm{s}}=9.07-\frac{19.99}{\mathrm{M}}+\frac{107.04}{\mathrm{M}^{2}}-\frac{72.06}{\mathrm{M}^{3}} \\
& \text { Desorption: } \mathrm{Q}_{\mathrm{s}}=8.01+\frac{21.27}{\mathrm{M}}+\frac{22.81}{\mathrm{M}^{2}}-\frac{19.28}{\mathrm{M}^{3}}
\end{aligned}
$$

From these equations, the energy of hysteresis loops was calculated. For this, the sorption heats were calculated for each water content (the point 0 was excluded for practical reasons) and at each temperature for each direction of sorption (adsorption and desorption). At each temperature and for each product, the sum of the differences in energy (desorption minus adsorption) was done.

Where there was a progressive and significant decrease of the hysteresis loop, energy loops were obtained by calculating the inverse of energy differences (desorption minus adsorption).

\section{RESULTS AND DISCUSSION}

Hysteresis loops: Adsorption and desorption isotherms of sheanut kernel and Canarium pulp at $25^{\circ} \mathrm{C}$ are shown in Fig. 1 and 2, respectively. Hysteresis phenomenon was observed irrespective of the temperature. This observation was repeated from $35-55^{\circ} \mathrm{C}$.

Monolayer intermolecular attraction $(Q)$ and hysteresis loops energies: Table 1 shows for example, the estimated values of $Q$ and those calculated from the energy of the hysteresis loop. Observation is the same at all water activities and moisture contents. In the case of sheanut kernel, differences amongst $Q$ generally remain constant through out the sorption temperature range studied. On the contrary, gradual and significant decrease of this difference was observed as far as Canarium pulp was concerned. Furthermore, the estimated monolayer intermolecular attraction energies indicated a difference of $0.67-0.02 \mathrm{~kJ} \mathrm{~mol}{ }^{1}{ }^{1}$ with increasing temperature. These values were lower than those obtained for sheanut kernels $\left(1.09-0.29 \mathrm{~kJ} \mathrm{~mol}^{\bullet}{ }^{1}\right)$.

Moreover, large hysteresis loop for sheanut kernel and its intermolecular attraction energy variations are indicative of the fact that dehydration of sheanut kernel

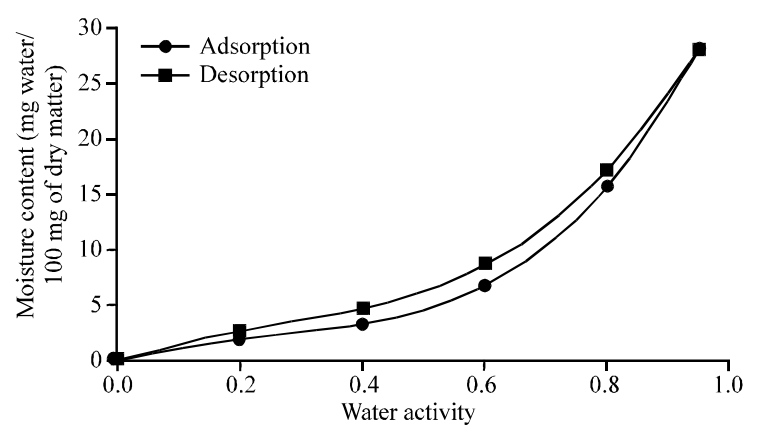

Fig. 1: Adsorption and desorption isotherms of sheanut kernel at $25^{\circ} \mathrm{C}$

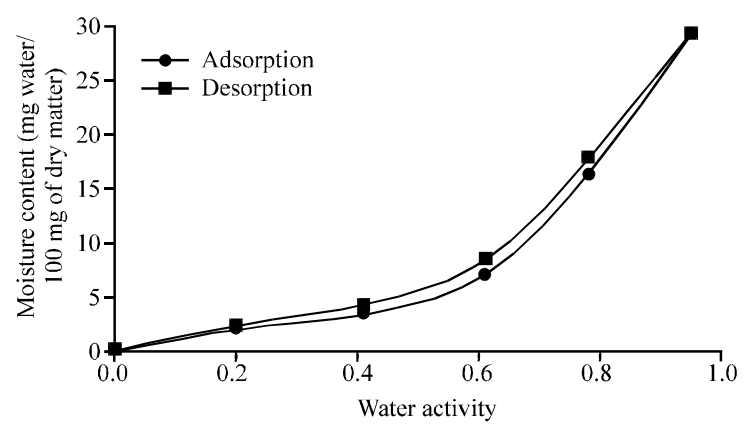

Fig. 2: Adsorption and desorption isotherms of Canarium pulp at $25^{\circ} \mathrm{C}$ 


\begin{tabular}{|c|c|c|c|c|c|c|c|c|c|c|c|}
\hline \multirow[b]{2}{*}{$\mathrm{T}\left({ }^{\circ} \mathrm{C}\right)$} & \multirow[b]{2}{*}{$\mathrm{a}$} & \multirow[b]{2}{*}{$\mathrm{m}_{\text {ads }}$} & \multirow[b]{2}{*}{$\mathrm{m}_{\mathrm{des}}$} & \multicolumn{2}{|c|}{ Sheanut kernel } & \multirow[b]{2}{*}{$\begin{array}{c}\cdot \mathrm{Q} \\
\left(\mathrm{kJ} \mathrm{mol}^{-1}\right)\end{array}$} & \multirow[b]{2}{*}{$\mathrm{m}_{\mathrm{ads}}$} & \multirow[b]{2}{*}{$\mathrm{m}_{\text {des }}$} & \multicolumn{2}{|c|}{ Canarium pulp } & \multirow[b]{2}{*}{$\underset{\left(\mathrm{kJ} \text { mol} •{ }^{1}\right.}{\cdot \mathrm{Q}}$} \\
\hline & & & & $\begin{array}{c}Q_{\text {ads }} \\
\left.\left(\mathrm{kJ} \mathrm{mol}^{1}\right)^{1}\right)\end{array}$ & $\begin{array}{c}\mathrm{Q}_{\mathrm{des}} \\
\left(\mathrm{kJ} \text { mol• }{ }^{1}\right)\end{array}$ & & & & $\begin{array}{c}\mathrm{Q}_{\mathrm{ads}} \\
\left(\mathrm{kJ} \text { mol} \bullet{ }^{1}\right)\end{array}$ & $\begin{array}{c}\mathrm{Q}_{\mathrm{des}} \\
\left(\mathrm{kJ} \text { mol }{ }^{1}\right)\end{array}$ & \\
\hline \multirow[t]{5}{*}{25} & 0.20 & 1.83 & 2.60 & 1.02 & 2.07 & 1.05 & 1.92 & 2.30 & 4.57 & 5.11 & 0.54 \\
\hline & 0.20 & 3.21 & 4.58 & 2.70 & 3.76 & 1.06 & 3.35 & 4.19 & 6.23 & 6.90 & 0.67 \\
\hline & 0.20 & 6.72 & 8.55 & 4.91 & 5.63 & 0.72 & 7.03 & 8.38 & 8.43 & 8.96 & 0.53 \\
\hline & 0.20 & 15.57 & 17.10 & 7.42 & 7.70 & 0.28 & 16.29 & 17.77 & 10.94 & 11.20 & 0.26 \\
\hline & 0.20 & 27.94 & 27.94 & 9.16 & 9.16 & 0.00 & 29.23 & 29.23 & 12.68 & 12.68 & 0.00 \\
\hline \multirow[t]{5}{*}{35} & 0.21 & 1.47 & 2.05 & 3.73 & 4.76 & 1.02 & 1.47 & 1.77 & 3.72 & 4.29 & 0.57 \\
\hline & 0.21 & 2.56 & 3.60 & 5.44 & 6.49 & 1.05 & 2.58 & 3.10 & 5.45 & 6.02 & 0.57 \\
\hline & 0.21 & 5.37 & 6.93 & 7.72 & 8.51 & 0.79 & 5.43 & 6.24 & 7.74 & 8.17 & 0.43 \\
\hline & 0.21 & 12.30 & 13.58 & 10.28 & 10.58 & 0.30 & 12.40 & 13.04 & 10.28 & 10.43 & 0.15 \\
\hline & 0.21 & 22.31 & 22.31 & 12.11 & 12.11 & 0.00 & 22.52 & 22.52 & 12.11 & 12.11 & 0.00 \\
\hline \multirow[t]{5}{*}{45} & 0.20 & 1.16 & 1.61 & 3.26 & 4.30 & 1.04 & 1.12 & 1.28 & 2.92 & 3.35 & 0.43 \\
\hline & 0.20 & 2.07 & 2.80 & 5.10 & 6.06 & 0.96 & 2.01 & 2.21 & 4.78 & 5.08 & 0.30 \\
\hline & 0.20 & 4.33 & 5.64 & 7.45 & 8.29 & 0.84 & 4.19 & 4.41 & 7.12 & 7.28 & 0.16 \\
\hline & 0.20 & 9.96 & 10.81 & 10.10 & 10.36 & 0.26 & 9.65 & 9.74 & 9.77 & 9.80 & 0.03 \\
\hline & 0.20 & 17.97 & 17.97 & 11.98 & 11.98 & 0.00 & 17.42 & 17.42 & 11.65 & 11.65 & 0.00 \\
\hline \multirow[t]{5}{*}{55} & 0.20 & 0.94 & 1.31 & 4.38 & 5.47 & 1.09 & 0.82 & 0.86 & 2.97 & 3.12 & 0.15 \\
\hline & 0.20 & 1.67 & 2.22 & 6.26 & 7.19 & 0.93 & 1.51 & 1.55 & 4.96 & 5.04 & 0.08 \\
\hline & 0.20 & 3.49 & 4.62 & 8.68 & 9.60 & 0.92 & 3.17 & 3.19 & 7.37 & 7.39 & 0.02 \\
\hline & 0.20 & 8.11 & 8.87 & 11.44 & 11.73 & 0.29 & 7.45 & 7.49 & 10.16 & 10.18 & 0.02 \\
\hline & 0.20 & 14.58 & 14.58 & 13.36 & 13.36 & 0.00 & 13.34 & 13.34 & 12.05 & 12.05 & 0.00 \\
\hline
\end{tabular}

$\mathrm{T}$ : Temperature; a: Water activity; $\mathrm{Q}_{\mathrm{ads}}: \mathrm{Q}$ in adsorption; $\mathrm{Q}_{\text {des }}: \mathrm{Q}$ in desorption; $\bullet \mathrm{Q}=\mathrm{Q}_{\text {des }}-\mathrm{Q}_{\mathrm{ads}}$

Table 2: Calculated hy steresis loop energy values

\begin{tabular}{lcc}
\hline \multicolumn{3}{l}{ Table 2: Calculated hy steresis loop energy values } \\
& Hysteresis loop energy $\left(\mathrm{kJ}\right.$ mol $\left.{ }^{1}\right)$ \\
\hline & $\left.-{ }^{2}\right)$ & Canarium pulp \\
\hline 25 & Sheanut kernel & 10.18 \\
35 & 103.60 & 9.48 \\
45 & 98.39 & 6.39 \\
55 & 88.61 & 2.94 \\
\hline
\end{tabular}

requires more energy than Canarium pulp. This was confirmed from the calculation of the hysteresis loop energy in the temperatures range used of study (Table 2). Results shown in Table 2 reflect the experimental reality, even if this method of calculating of the hysteresis loop energy does not take into account the extremities of the loop. These results indicate that drying of kernel requires more energy than that of pulp. Furthermore, these results confirm those reported by Nkouam who demonstrated that fresh sheanut kernels had a harder texture than Canarium pulp.

\section{CONCLUSION}

The estimated monolayer intermolecular attraction energies values of sheanut kernel are superior to those of Canarium pulp through out the temperature range studied. The energies of hysteresis loops of the sheanut kernel are higher than those of the Canarium pulp at all temperatures. These results suggest that drying of sheanut kernels requires more energy than Canarium pulp.

\section{ACKNOWLEDGEMENTS}

The researchers gratefully acknowledge the Agence Universitaire de la Francophonie (AUF) for its support through a research grant. They also acknowledge Professor Matthew Caurie (Department of Home Economics Education, University of Education, Winneba, P.O. Box 25, Winneba, Ghana) for its kind advices and collaboration.

\section{REFERENCES}

Booth, S.F.M. and G.E.Wickens, 1988. Non-Timbers Uses of Selected Arid Zone Trees and Shrubs in Africa. FAO, Rome, pp: 34-45.

Caurie, M., 2005. The unimolecular character of the classical Brunauer, Emmett and Teller adsorption equation and moisture adsorption. Int. J. Food Sci. Technol., 40: 283-293.

Caurie, M., 2007. Hysteresis phenomenon in foods. Int. J. Food Sci. Technol., 42: 45-49.

Kapseu, C., G.B. Nkouam, M. Dirand, D. Barth, L. Perrin and C. Tchiegang, 2006. Water vapour sorption isotherms of sheanut kernels (Vitellaria paradoxa Gaertn.). J. Food Technol., 4: 235-241.

Wang, N. and J.G. Brennan, 1991. Moisture sorption isotherm characteristics of potatoes at four temperatures. J. Food Eng., 14: 269-287. 